\section{Medical Principles and Practice}

Med Princ Pract 2017;26:35-40

DOI: 10.1159/000450644
Received: July 21, 2015

Accepted: September 7, 2016

Published online: September 7, 2016

\title{
Factors Affecting Adherence to Statins in Hypercholesterolemic Kuwaiti Patients: A Cross-Sectional Study
}

\author{
Meisa Al-Foraih ${ }^{a}$ Shawn Somerset ${ }^{b}$

 \\ University, Brisbane, Qld., Australia
}

\section{Key Words}

Statins · Adherence $\cdot$ Hypercholesterolemia

\begin{abstract}
Objective: This study examined statin adherence amongst Kuwaiti hypercholesterolemic patients in order to identify factors associated with poor adherence and to determine whether or not an association exists between statin adherence and the risk profile of coronary heart disease (CHD). Subjects and Methods: Two hundred hypercholesterolemic patients (30-69 years of age) were recruited from Kuwaiti primary healthcare clinics and interviewed about demographic characteristics, pre-existing self-reported medical conditions and prescribed medications. The Morisky Medication Adherence Scale was used to assess statin adherence (a self-reported, medication-adherence questionnaire divided into 3 levels, with a score of 8 denoting high adherence, 6 to $<8$ denoting medium adherence and $<6$ denoting low adherence). Data regarding anthropometric, psychological and serum risk factors were collected using 2 additional questionnaires, laboratory tests and bioelectrical impedance scales. Binary logistic regression was used to determine predictors of adherence and general linear modelling was used to test relationships between continuous outcomes and statin adherence. Results: Of the 200 participants, 117 (58.5\%) reported low adherence, 83 (41.5\%) reported medi-
\end{abstract}

\begin{tabular}{ll}
\hline KARGER & ( 2016 S. Karger AG, Basel \\
$\begin{array}{l}\text { E-Mail karger@karger.com } \\
\text { www.karger.com/mpp }\end{array}$ & $\begin{array}{l}\text { This is an Open Access article licensed under the terms of the } \\
\text { Creative Commons Attribution-NonCommercial 3.0 Un- } \\
\text { ported license (CC BY-NC) (www.karger.com/OA-license), } \\
\text { applicable to the online version of the article only. Distribu- } \\
\text { tion permitted for non-commercial purposes only. }\end{array}$
\end{tabular}

um adherence and no patients (0\%) scored high adherence. Younger patients (aged 30-50 years) had lower adherence than older patients (>50 years) [odds ratio (OR) 1.05; 95\% confidence interval (CI) 1.01-1.09] for every extra year; $\mathrm{p}<$ 0.01). Those without diabetes, i.e. 113 (56.5\%), were less likely to report medium adherence than those with diabetes (OR $0.42 ; 95 \% \mathrm{Cl} 0.23-0.75 ; \mathrm{p}<0.01)$. Low statin adherence was associated with higher levels of plasma cholesterol ( $p<$ 0.001 ) and low-density lipoprotein $(p<0.01)$. Conclusion: In this study, there was a high prevalence of low statin adherence, especially among younger patients with fewer concomitant diseases. The results indicated an inverse relationship between statin adherence and CHD risk profile.

๑) 2016 S. Karger AG, Basel

\section{Introduction}

Cardiovascular diseases are recognised as major contributors to global mortality and morbidity. Coronary heart disease (CHD) has emerged as the leading cause of premature death worldwide, each year claiming approximately 3.8 and 3.4 million deaths of men and women, respectively [1]. CHD continues to be a major health issue in Kuwait, with an increasingly significant prevalence over the years and mean onset of the disease appearing at a younger age [2]. This is apparent in a systematic review 
by Elshourbagy et al. [3], who reported heart disease as being most common among people aged $\geq 65$ years and also an increase in the number of sudden deaths from heart disease among younger individuals (15-34 years).

Hypercholesterolemia is associated with an increased risk of CHD [4]. Practices for efficacious prevention of CHD include lifestyle changes and life-long statin therapy; however, poor adherence limits the benefits of these drugs [4]. Adherence is a key factor associated with the efficacy of all pharmacological therapies, including statins [5]. Liberopoulos et al. [6] identified high rates of discontinuation of statin therapy as a major health issue associated with unfavourable cardiovascular outcome; they reported that as many as $60 \%$ of their patients stopped taking statins during the first 6 months following the initiation of the treatment.

Common determinants of poor statin adherence include a lack of education, poor trust of the physician, undesired side effects and inadequate provider-patient communication [7]. Accordingly, a randomized controlled trial by Yilmaz et al. [8] indicated that being well-informed about statins increased the likelihood of continuity of statin therapy at 15 months post-prescription by approximately 2 -fold. This finding indicated that providing patients with comprehensive knowledge about statins seemed not only to improve adherence but also to increase the likelihood of reaching targets [8].

Although statin prescription for hypercholesterolemia is common in the Gulf region [9], there is no published account of statin adherence and its potential determinants specific to these populations. This study aimed to assess the prevalence of statin adherence, the factors associated with adherence and the risk profile trends of $\mathrm{CHD}$ associated with low adherence in patients prescribed statins in Kuwait.

\section{Subjects and Methods}

Participants and Recruitment

Twelve polyclinic/general practice clinics across 4 of the 6 governorates in Kuwait (i.e. Al Asimah, Al-Farwaniya, Hawalli and Mubarak Al-Kabir) were visited for this study. Consecutive patients (any health condition) attending these clinics from October 2011 to October 2012 were approached until a sufficient number of patients per clinic was assessed. The sample size was determined using the modified version of the approach advocated by Green [10], which is as follows: $n>50+8 k$, where ' $k$ ' is the number of parameters included in the model (i.e. adherence, age, gender and governorate). There are 16 parameters associated with the main effects, yielding a proposed sample size of $\mathrm{n}=50+8 \times 16=178$. Consequently, a sample size of $\mathrm{n}=200$ was used. Participants were informed of the purpose of the study, the benefits of the research and any risks associated with participation, and were then asked to provide both verbal and written consent. Ethical approval was obtained from the Griffith University Human Research Ethics Committee and the Medical Research Ethics Committee in the Kuwait Institute of Medical Specialisation within the Ministry of Health in Kuwait.

A brief, face-to-face screening was conducted (by M.F.) to select subjects suitable for the study, based on the following inclusion criteria: Kuwaitis of both genders, aged 30-69 years, living in both urban and rural governorates, having hyperlipidemia (classified as total serum cholesterol levels of $>7.8 \mathrm{mmol} / \mathrm{l}$ ) [13] but free of diagnosed CHD and on prescribed statins for at least 6 months prior to the first interview (the initiation of statin therapy for patients involved in the study ranged between 6 and 24 months prior to study participation). Accordingly, 200 patients were chosen. Data on demographic characteristics, pre-existing self-reported medical conditions (e.g. hypercholesterolemia, hypertension and diabetes) and prescribed medications were also collected from the participants. Patients' medical records were reviewed to confirm the selfreports. The data collected by these 2 methods were then combined for analysis.

\section{Data Assessment}

Three questionnaires were used to collect the relevant data. The first was on sociodemographic and clinical factors including age, gender, work status, governorate, smoking status, current or past use of all medications, duration and type of statin intake and previous diabetic/hypertensive conditions. The second consisted of the Depression, Anxiety and Stress Scale (DASS) [14], used (by M.F.) to assess affective disorder status. Interpretation of the DASS was based primarily on the use of cut-off scores provided by Lovibond and Lovibond [15]: severity ratings were classified as normal (D 0-9, A 0-7, S 0-14), mild (D 10-13, A 8-9, S 15-18), moderate (D 14-20, A 10-14, S 19-25), severe (D 21-27, A 15-19, S 26-33) and extremely severe (D 28+, A 20+, S 34+) on the basis of combined collective scores in every subscale category [15]. The third was the 8-item self-report Morisky Medication Adherence Scale (MMAS) [16], used to measure adherence levels to statin therapy, i.e. atorvastatin (Lipitor), simvastatin (Zocor) or rosuvastatin (Crestor). The MMAS score was divided into 3 levels of adherence: $8=$ high, 6 to $<8=$ medium and $<6=$ low [16]. Permission to use the MMAS was granted by David E. Morisky himself, hence, a waiver of licensure fee was also received (permission submitted).

An anthropometric assessment was also conducted. Initially, height and weight were measured using a Seca 217 stadiometer (Hamburg, Germany) [17], and the Omron body fat analyser, Model HBF-500 (Omron Medizintechnik, Mannheim, Germany) [18], respectively. Bioelectrical impedance assessment was then carried out, by which the participant's height, gender and age were entered into the Omron body fat analyser, Model HBF-500. This device uses 8 electrodes in a tetrapolar arrangement that requires the subject to stand on metal footpads in bare feet and grasp a pair of electrodes fixed on a handle with arms extended in front of the chest [18]. They are instructed to hold the analyser according to the manufacturer's directions (arms extended from body and perpendicular to the floor, thumbs on top). The estimate of body fat percentage and skeletal muscle mass were recorded, along with the computed BMI value. Subjects were categorised according to the following: underweight $=$ BMI $<20.0$, healthy $=$ BMI 20.0-24.9, overweight $=$ BMI 25.0-29.9 and obese $=$ BMI $>30.0$.
Med Princ Pract 2017;26:35-40 DOI: $10.1159 / 000450644$
Al-Foraih/Somerset 
Table 1. Socio-demographic factors of the 200 participants

\begin{tabular}{lc}
\hline Gender & $\mathrm{n}(\%)$ \\
\hline Male & $63(31.5)$ \\
Female & $137(68.5)$ \\
Age category & \\
$\quad 30-50$ years & $56(28)$ \\
$51-60$ years & $75(37.5)$ \\
$\quad 61-69$ years & $69(34.5)$ \\
Governorate & $125(62.5)$ \\
$\quad$ Al-Asimah & $61(30.5)$ \\
Hawalli & $11(5.5)$ \\
$\quad$ Al-Farwaniya & $3(1.5)$ \\
Mubarak Al-Kabir & \\
Work status & $54(27)$ \\
Yes & $146(73)$ \\
No & $117(58.5)$ \\
Adherence level & $83(41.5)$ \\
Low $(<6)$ & $0(0)$ \\
Medium $(6$ to $<8)$ & \\
High $(8)$ &
\end{tabular}

In addition, a risk profile for each patient was constructed from serum risk factor measurements in medical records collected as part of usual care. These included a complete lipid profile and blood chemistry, i.e. levels of glucose, serum cholesterol, triglycerides, high-density lipoprotein (HDL), low-density, lipoprotein (LDL) and very-low-density lipoprotein (VLDL) cholesterol in the blood. Factors that increased the risk of developing CHD [19-21] were based on $\geq 1$ of the following criteria: blood glucose $\geq 6.1$ $\mathrm{mmol} / \mathrm{l}$, hypertriglyceridemia $\geq 1.69 \mathrm{mmol} / \mathrm{l}$, HDL cholesterol $<1.04 \mathrm{mmol} / \mathrm{l}$ in men and $<1.29 \mathrm{mmol} / \mathrm{l}$ in women, and LDL cholesterol $\geq 3.4 \mathrm{mmol} / \mathrm{l}$.

\section{Statistical Analysis}

All analyses were performed using STATA (Statistics and Data v11.0, Stata Corp., College Station, Tex., USA) [22] Descriptive analysis using cross-tabulations (contingency tables) were initially carried out to establish an interdependent relationship between various research variables, such as statin adherence and age, gender, area of residence and work status. Binary logistic regression was then used to determine predictors of the dichotomous variable, statin adherence (low/medium). Associations between risk factors and the outcomes were gauged using odds ratios (ORs). Independent Student's t tests and general linear modelling were used to test relationships between continuous outcomes (e.g. blood chemistry) and statin adherence (categorical variables). Model building was performed using a modified version of the Purposeful Selection of Covariates (PSC) approach outlined by Hosmer et al. [23]. The PSC was modified to consider a study effect where gauging the significance of a particular risk factor was the primary outcome (i.e. statin adherence) with identifying other risk factors as secondary outcomes (i.e. blood chemistry). Statin adherence was therefore forced into each step of this 3-step model, regardless of its statistical significance, to ensure that the research hypothesis was being addressed. However, when statin adherence was measured as an outcome, the exact model-building
Table 2. Gender-specific subject distribution of anthropometric variables

\begin{tabular}{|c|c|}
\hline Male & $63(31.5)$ \\
\hline Fat range, $\%$ & $19.8-45.5$ \\
\hline \multicolumn{2}{|l|}{ Percentage body fat } \\
\hline Underweight & $0(0)$ \\
\hline Healthy & $2(3.2)$ \\
\hline Overweight & $12(19)$ \\
\hline Obese & $49(77.8)$ \\
\hline Female & $137(68.5)$ \\
\hline Fat range, $\%$ & $25.8-58.5$ \\
\hline \multicolumn{2}{|l|}{ Percentage body fat } \\
\hline Underweight & $0(0)$ \\
\hline Healthy & $9(6.6)$ \\
\hline Overweight & $11(8)$ \\
\hline Obese & $117(85.4)$ \\
\hline \multicolumn{2}{|c|}{ Mean sex distribution $\pm \mathrm{SD}, \%$} \\
\hline Males & $32.4 \pm 5.03$ \\
\hline Females & $46.1 \pm 6.03$ \\
\hline Male & $63(31.5)$ \\
\hline Range & $21.8-44.5$ \\
\hline \multicolumn{2}{|l|}{ BMI } \\
\hline Underweight & $0(0)$ \\
\hline Normal & $4(6.3)$ \\
\hline Overweight & $24(38.1)$ \\
\hline Obese & $33(52.4)$ \\
\hline Extremely obese & $2(3.2)$ \\
\hline Female & $137(68.5)$ \\
\hline Range & $21.9-57.2$ \\
\hline \multicolumn{2}{|l|}{ BMI } \\
\hline Underweight & $0(0)$ \\
\hline Normal & $9(6.6)$ \\
\hline Overweight & $42(30.7)$ \\
\hline Obese & $70(51.1)$ \\
\hline Extremely obese & $16(11.7)$ \\
\hline \multicolumn{2}{|c|}{ Mean sex distribution $\pm \mathrm{SD}, \%$} \\
\hline Males & $31.1 \pm 4.49$ \\
\hline Females & $32.4 \pm 6.34$ \\
\hline
\end{tabular}

Values express n (\%), unless otherwise indicated. Percentage body fat was measured using an Omron body fat analyser.

protocol advocated by Hosmer et al. [23] was employed, since there was no single-study effect and the modelling process became more exploratory (determination of risk factors associated with adherence).

\section{Results}

The distribution of subjects based on socio-demographic characteristics is shown in table 1. According to the Yes/No answers provided by the participants regarding smoking, 177 of the 200 participants (88.5\%) reported 
Table 3. Gender-specific subject distribution of clinical variables

\begin{tabular}{cclrrrr} 
& $\begin{array}{l}\text { Mean } \pm \\
\text { SD, } \\
\text { mmol/1 }\end{array}$ & $\begin{array}{l}\text { Reading, } \\
\text { mmol/l } \\
\text { (range) }\end{array}$ & & & \multicolumn{3}{l}{$\begin{array}{l}\text { Treatment } \\
\text { adherence, \% }\end{array}$} \\
\cline { 5 - 8 } & & & & low & normal high \\
\hline Cholesterol & $4.9 \pm 1.2$ & $2.5-8.9$ & 200 & 1.5 & 66.5 & 32 \\
Males & $5.1 \pm 1.4$ & $2.5-8.9$ & 63 & 3.2 & 54 & 42.9 \\
Females & $4.8 \pm 1$ & $2.6-7.7$ & 137 & 0.7 & 72.3 & 27 \\
Triglycerides & $1.8 \pm 2.5$ & $0.34-35.1$ & 197 & 0.5 & 80.2 & 19.3 \\
Males & $2.4 \pm 4.3$ & $0.50-35.1$ & 62 & 0 & 69.4 & 30.6 \\
Females & $1.5 \pm 0.8$ & $0.34-6.4$ & 135 & 0.7 & 85.2 & 14.1 \\
HDL & $1.3 \pm 0.3$ & $0.57-2.6$ & 180 & 20 & 77.2 & 2.8 \\
Males & $1 \pm 0.2$ & $0.68-1.7$ & 55 & 40 & 60 & 0 \\
Females & $1.3 \pm 0.3$ & $0.57-2.6$ & 125 & 11.2 & 84.8 & 4 \\
LDL & $2.9 \pm 1$ & $0.7-6$ & 178 & 43.2 & 32.4 & 24.4 \\
Males & $3 \pm 1.2$ & $0.7-5.8$ & 53 & 34.6 & 30.8 & 34.6 \\
Females & $2.8 \pm 0.96$ & $1.3-6$ & 125 & 46.8 & 33.1 & 20.2 \\
VLDL & $0.8 \pm 1.4$ & $0.14-14.1$ & 101 & 39.6 & 58.4 & 2 \\
Males & $1.3 \pm 2.6$ & $0.26-14.1$ & 27 & 25.9 & 70.4 & 3.7 \\
Females & $0.7 \pm 0.4$ & $0.14-2.9$ & 74 & 44.6 & 54.1 & 1.4 \\
\hline
\end{tabular}

Table 4. ORs of associations between adherence to statin medication and various demographic and clinical factors

\begin{tabular}{|c|c|c|c|c|}
\hline \multirow[t]{2}{*}{ Predictor variables } & \multirow[t]{2}{*}{$\begin{array}{l}\beta_{\text {Crude }} \\
(\text { OR) }\end{array}$} & \multirow[t]{2}{*}{$\begin{array}{l}\beta_{\text {Adjusted }} \\
(\mathrm{OR})\end{array}$} & \multicolumn{2}{|c|}{$\begin{array}{l}\text { 95\% CI for } \\
\text { difference* }\end{array}$} \\
\hline & & & lower & upper \\
\hline Age & $1.05^{* *}$ & $1.05^{* *}$ & 1.01 & 1.09 \\
\hline Gender & 0.92 & 0.74 & 0.36 & 1.57 \\
\hline Hawalli & 1.07 & & & \\
\hline Al-Farwaniya & 1.21 & & & \\
\hline Mubarak Al-Kabir & 0.73 & & & \\
\hline Work status & 0.62 & & & \\
\hline Smoker & 0.91 & 0.69 & 0.23 & 2.07 \\
\hline Diabetes & $0.4^{* *}$ & $0.42^{* *}$ & 0.23 & 0.75 \\
\hline Hypertension & $0.50^{*}$ & & & \\
\hline Zocor & 1.64 & & & \\
\hline Crestor & 0.29 & & & \\
\hline Statin duration & $1.04^{*}$ & & & \\
\hline Depression & 0.98 & & & \\
\hline Anxiety & 0.96 & & & \\
\hline Stress & 0.99 & & & \\
\hline$\chi_{\text {LR }}^{2}($ d.f. $=4)$ & & 17.97 & & \\
\hline $\mathrm{p}$ value $\left(\chi_{\mathrm{LR}}^{2}\right)$ & & 0.0013 & & \\
\hline
\end{tabular}

Al-Asimah and treatment with atorvastatin are not shown in the table as they are the referents (the group against which the others are compared) for the remaining governorates (Hawalli, AlFarwaniya, Mubarak Al-Kabir) and statins (Zocor, Crestor). ${ }^{*} \mathrm{p}<0.05,{ }^{* *} \mathrm{p}<0.01$. being non-smokers, 23 (11.5\%) reported smoking tobacco and only 1 was female.

A high prevalence of obesity was identified in our subjects, indicated by body fat percentage, in 49 (77.8\%) males and 117 (85.4\%) females, and BMI measurement, in $35(55.6 \%)$ males and $86(62.8 \%)$ females (table 2). Gender-specific subject distributions for anthropometric and clinical measures are presented in tables 2, 3 .

Depression, anxiety and stress cut-off points were a cumulative score of 21-27 points on the DASS 4-point Likert scale for depression, 15-19 for anxiety and 34+ for stress [15]. Of the 200 participants, $1(2 \%), 21(10.5 \%)$ and $6(3 \%)$ exceeded the cut-off points for depression, anxiety and stress, respectively.

Of the 200 participants, 87 (43.5\%) reported having diabetes, 84 (42\%) reported being hypertensive, 73 $(36.5 \%)$ reported being free of both diabetes and hypertension and $44(22 \%)$ reported having both.

Of the 200 participants, $117(58.5 \%)$ reported low adherence, $83(41.5 \%)$ reported medium adherence and none reported high adherence (table 1). Twenty-seven male (42.9\%) and 56 female (40.9\%) subjects had a higher statin adherence. However, based on the two-way contingency analysis, the difference was not statistically significant.

Preliminary bivariate analysis revealed 4 statistically significant predictors of statin adherence: age, diabetes, hypertension and the duration of statin intake. However, after adjusting for the confounders, gender, smoking and diabetes, in the final multivariable model, both age and diabetes remained associated with statin adherence level. The odds of medium adherence were 1.05 times [95\% confidence interval (CI) 1.01-1.09] higher than that of low adherence for every extra year of age ( $p<0.01$; table 4). Participants without diabetes had 0.42 times ( $95 \%$ CI 0.23-0.75) the odds of medium adherence (lower odds of medium adherence), relative to those with diabetes $(\mathrm{p}<0.01$; table 4$)$.

Low statin adherence was associated with higher plasma cholesterol at $\mathrm{p}<0.001$ and $\mathrm{p}<0.01$, for males and females, respectively, and higher LDL cholesterol levels at $\mathrm{p}<0.01$ for both males and females (table 5).

\section{Discussion}

In this study on patients with hypercholesterolemia, statin adherence was generally poor. Based on the MMAS, not one of the 200 subjects was classified as highly adherent to statin therapy, and more than half were classified 
Table 5. Gender-specific associations between statin adherence and biochemical outcomes

\begin{tabular}{|c|c|c|c|}
\hline Outcome & $\begin{array}{l}\text { Adherence } \\
\text { level }\end{array}$ & Mean & $\begin{array}{l}\text { Mean difference } \\
(95 \% \mathrm{CI})^{*}\end{array}$ \\
\hline \multicolumn{4}{|l|}{ Males } \\
\hline Cholesterol & $\begin{array}{l}\text { low } \\
\text { medium }\end{array}$ & $\begin{array}{l}5.53 \\
4.53\end{array}$ & $1.0(0.33 \text { to } 1.66)^{* * *}$ \\
\hline TG & $\begin{array}{l}\text { low } \\
\text { medium }\end{array}$ & $\begin{array}{l}1.78 \\
3.21\end{array}$ & $-1.43(-3.64$ to 0.77$)$ \\
\hline HDL & $\begin{array}{l}\text { low } \\
\text { medium }\end{array}$ & $\begin{array}{l}1.14 \\
0.93\end{array}$ & $0.21(0.09 \text { to } 0.33)^{* *}$ \\
\hline LDL & $\begin{array}{l}\text { low } \\
\text { medium }\end{array}$ & $\begin{array}{l}3.44 \\
2.60\end{array}$ & $0.84(0.26 \text { to } 1.42)^{* *}$ \\
\hline VLDL & $\begin{array}{l}\text { low } \\
\text { medium }\end{array}$ & $\begin{array}{l}0.77 \\
1.71\end{array}$ & $-0.93(-2.98$ to 1.11$)$ \\
\hline \multicolumn{4}{|l|}{ Females } \\
\hline Cholesterol & $\begin{array}{l}\text { low } \\
\text { medium }\end{array}$ & $\begin{array}{l}5.02 \\
4.42\end{array}$ & $0.60(0.25 \text { to } 0.95)^{* *}$ \\
\hline TG & $\begin{array}{l}\text { low } \\
\text { medium }\end{array}$ & $\begin{array}{l}1.43 \\
1.52\end{array}$ & $-0.09(-0.37$ to 0.19$)$ \\
\hline HDL & $\begin{array}{l}\text { low } \\
\text { medium }\end{array}$ & $\begin{array}{l}1.35 \\
1.34\end{array}$ & $0.01(-0.11$ to 0.13$)$ \\
\hline LDL & $\begin{array}{l}\text { low } \\
\text { medium }\end{array}$ & $\begin{array}{l}3.01 \\
2.40\end{array}$ & $0.61(0.28 \text { to } 0.94)^{* *}$ \\
\hline VLDL & $\begin{array}{l}\text { low } \\
\text { medium }\end{array}$ & $\begin{array}{l}0.69 \\
0.70\end{array}$ & $-0.01(-0.21$ to 0.20$)$ \\
\hline
\end{tabular}

$\mathrm{TG}=$ Triglycerides. ${ }^{*} \mathrm{p}<0.05,{ }^{* *} \mathrm{p}<0.01,{ }^{* * *} \mathrm{p}<0.001$
Higher adherence to statin therapy was inversely associated with plasma cholesterol and LDL levels, with overall effect size values of -12.7 and $-19.2 \%$, respectively, suggesting that these differences may also be of clinical importance.

Furthermore, subjects who had been on statin medication longer had lower plasma cholesterol, glucose and LDL levels. Hence, statin prescription was effective in lowering CHD risk. Psychosocial factors were not associated with statin adherence in our study, thus contradicting findings from previous studies that recognised depression as one of the most important factors affecting adherence to medical treatment [27-30]. Our results revealed no significant difference in adherence between depressed and non-depressed patients; a study by Weilburg et al. [28] indicated that depressed hyperlipidemic diabetic patients refilled their statin prescriptions less often than those without depression; this suggests lower adherence [28]. Their study also revealed that patients receiving adequate anti-depressants were twice as likely to adhere to chronicdisease medications (including statins) than patients receiving inadequate anti-depressant treatment [28]. In addition, a study by Sulaiman et al. [29] revealed that depressed Arab patients in the United Arab Emirates were less likely to adhere to prescribed healthcare regimens.

\section{Conclusion}

In this study, there was an inverse relationship between high adherence to statin therapy and plasma levels of cholesterol and LDL, suggesting that statin prescription is effective in improving CHD risk profile. Subjects with concomitant diabetes were more responsive to statin therapy, while younger patients with fewer concurrent diseases showed lower treatment adherence. Future research is required to establish the reasons for the differences in adherence between various Kuwaiti subject groups and to determine how to enhance overall statin adherence in the early stages of prescription.

tory of diabetes confirmed those of Latry et al. [26] who reported higher adherence in those patients with an increased number of associated cardiovascular risk factors including older age, diabetes and other cardiovascular disease comorbidities. They suggested that older patients with several risk factors were probably more aware of their own mortality and thus more attentive to their treatment than younger patients. It is also plausible that patients with diabetes had experienced the consequence of non-adherence to a specific medication, and hence be more aware and attuned to these health consequences.
1 Gaziano TA, Bitton A, Anand S, et al: Growing epidemic of coronary heart disease in lowand middle-income countries. Curr Probl Cardiol 2010;35:72-115.

2 Awad AI, Alsaleh FM: 10-Year Risk estimation for type 2 diabetes mellitus and coronary heart disease in Kuwait: a cross-sectional population-based study. PLoS One 2015; 10:e0116742.

\section{References}


3 Elshourbagy NA, Meyers HV, Abdel-Meguid SS: Cholesterol: the good, the bad, and the ugly - therapeutic targets for the treatment of dyslipidemia. Med Princ Pract 2013;23:99111.

4 Mann DM, Woodward M, Muntner P, et al: Predictors of nonadherence to statins: a systematic review and meta-analysis. Ann Pharmacother 2010;44:1410-1421.

5 Brown MT, Bussell JK: Medication adherence: WHO cares? Mayo Clin Proc 2011;86: 304-314.

6 Liberopoulos EN, Florentin M, Mikhailidis DP, et al: Compliance with lipid-lowering therapy and its impact on cardiovascular morbidity and mortality. Expert Opin 2008; 717-725.

7 Pedan A, Varasteh LT, Schneeweiss S: Analysis of factors associated with statin adherence in a hierarchical model considering physician, pharmacy, patient, and prescription characteristics. J Manag Care Pharm 2007;13: 487-496.

8 Yilmaz MB, Pinar M, Naharci I, et al: Being well-informed about statin is associated with continuous adherence and reaching targets. Cardiovasc Drugs Ther 2005;19:437-440.

9 Al Sifri SN, Almahmeed W, Azar S, et al: Results of the Dyslipidemia International Study (DYSIS) - Middle East: clinical perspective on the prevalence and characteristics of lipid abnormalities in the setting of chronic statin treatment. PLoS One 2014;9:e84350.

10 Green SB: How many subjects does it take to do a regression analysis. Multivariate Behav Res 1991;26:499-510.

11 Al-Isa A: Temporal changes in body mass index and prevalence of obesity among Kuwaiti men. Ann Nutr Metab 1997;41:307-314.
12 Bu-Olayan A, Thomas B: Dispersion model on PM 2.5 fugitive dust and trace metal levels in Kuwait governorates. Environ Monit Assess 2012;184:1731-1737.

13 Grover SA, Abrahamowicz M, Joseph L, et al: The benefits of treating hyperlipidemia to prevent coronary heart disease. Estimating changes in life expectancy and morbidity. JAMA 1992;267:816-822.

14 Crawford JR, Henry JD: The depression anxiety stress scale (DASS): normative data and latent structure in a large non-clinical sample. Br J Clin Psychol 2003;42:111-131.

15 Lovibond SH, Lovibond PF: Manual for the Depression, Anxiety, Stress Scales. Sydney, Psychology Foundation, 1995.

16 Morisky DE, Ang A, Krousel-Wood M, et al: Predictive validity of a medication adherence measure for hypertension control. J Clin $\mathrm{Hy}$ pertens 2008; 10:348-354.

17 Ihmels M, Welk GJ, McClain JJ, et al: The reliability and convergent validity of field tests of body composition in young adolescents. J Phys Act Health 2006;3:67-77.

18 Bosy-Westphal A, Later W, Hitze W, et al: Accuracy of bioelectrical impedance consumer devices for measurement of body composition in comparison to whole body magnetic resonance imaging and dual X-ray absorptiometry. Obes Facts 2008;1:319-324.

19 Ford ES, Giles WH, Dietz WH: Prevalence of the metabolic syndrome among US adults: findings from the Third National Health and Nutrition Examination Survey. JAMA 2002; 287:356-359.

20 Lakka H-M, Laaksonen DE, Lakka TA, et al: The metabolic syndrome and total and cardiovascular disease mortality in middle-aged men. JAMA 2002;288:2709-2716.
21 Grubb NR, Newby DE: Churchill's Pocketbook of Cardiology. Edinburgh, Churchill Livingstone, 2006.

22 STATA statistical software: release 11. College Station, StataCorp, 2009.

23 Hosmer DW, Lemeshow S, May S: Applied survival analysis; in: Wiley Series in Probability and Statistics. Hoboken, Wiley, 2008.

24 Natarajan N, Putnam RW, Yip AM, et al: Family practice patients' adherence to statin medications. Can Fam Physician 2007;53: 2144-2145.

25 Cutler DM, Jan S, Fischer MA, et al: Patient, Physician, and Payment Predictors of Statin Adherence. Cambridge, Harvard University Department of Economics, 2010.

26 Latry P, Molimard M, Dedieu B, et al: Adherence with statins in a real-life setting is better when associated cardiovascular risk factors increase: a cohort study. BMC Cardiovasc Disord 2011;11:46.

27 Ziegelstein RC, Howard B: Depression and poor adherence to lipid-lowering medications among patients with coronary artery disease. J Psychosom Res 2010;69:175-177.

28 Weilburg JB, O’Leary KM, Grant RW: Impact of antidepressant therapy on statin adherence and cholesterol control. Am J Pharm 2009;1: 158-163.

29 Sulaiman N, Hamdan A, Tamim H, et al: The prevalence and correlates of depression and anxiety in a sample of diabetic patients in Sharjah, United Arab Emirates. BMC Fam Pract 2010;11:80-86.

30 Somerset SM, Graham L, Markwell KE: Depression scores predict adherence in a dietary weight loss intervention trial. Clin Nutr 2011; 30:593-598. 